\title{
Effect of Dietary Polyphenols from Hop (Humulus lupulus L.) Pomace on Adipose Tissue Mass, Fasting Blood Glucose, Hemoglobin A1c, and Plasma Monocyte Chemotactic Protein-1 Levels in OLETF Rats
}

\author{
Kazuki Yui, Hiroki Uematsu, Keisuke Muroi, Kazuhiro Ishii, Minako Baba and \\ Kyoichi Osada*
}

Department of Agricultural Chemistry, School of Agriculture, Meiji University (1-1-1 Higashimita, Tama-ku, Kawasaki, Kanagawa 214-8571, JAPAN)

\begin{abstract}
Hop (Humulus lupulus L.) pomace contains procyanidin-rich polyphenols, which are large oligomeric compounds of catechin. We studied the effect of high dose $(1 \%)$ of dietary hop pomace polyphenols (HPs) in Otsuka Long-EvansTokushima Fatty (OLETF) rats, an animal model of type 2 diabetes. By 70 days, the rats fed HPs tended to have a lower body weight and reduced mesenteric white adipose tissue weight than the rats fed a control diet. Triglyceride levels in both plasma and liver tended to be lower in the HPs-fed group than in the control group. Dietary HPs substantially suppressed the activities of hepatic fatty acid synthetase, glucose-6-phosphate dehydrogenase, and malic enzyme, through the suppression of SREBP1c mRNA expression in OLETF rats. Moreover, in the HPs-fed group, monocyte chemotactic protein-1 (MCP-1) expression and fasting blood glucose levels at 40 days, and hemoglobin A1c (HbA1c) levels at 70 days were significantly lower than those in the control group. Thus, dietary HPs may exert an ameliorative function on hepatic fatty acid metabolism, glucose metabolism, and inflammatory response accompanying the increase of the adipose tissue mass in OLETF rats.
\end{abstract}

Key words: Hop, procyanidin, obesity, fatty acid metabolism, rat, OLETF

\section{INTRODUCTION}

Obesity has become increasingly prevalent worldwide because of changes in lifestyle, including changes in dietary habits, alcohol consumption, and physical activity ${ }^{1-3}$. Obesity increases the risk for disease such as type 2 diabetes, cardiovascular disease, and some types of cancer ${ }^{4-6)}$.

Some dietary components can prevent or ameliorate obesity and thereby can reduce the risk for lifestyle diseases. Polyphenols are a large and diverse class of compounds, many of which occur naturally in components of the human diet, such as beans, cereals, fruits, vegetables, and red wine $^{7)}$. There is a growing interest in the biological properties of polyphenols and their role in the prevention or amelioration of lifestyle diseases; of these, tea catechins have been extensively studied. Tea catechins appear to have anti-oxidant activities, anti-obesity effects, and can improve insulin resistance ${ }^{8-11)}$. In addition, quercetin contained in onions exerts anti-oxidant activity ${ }^{12)}$, whereas anthocyani- dins from black soybean improve insulin resistance ${ }^{13)}$. Hops (Humulus lupulus L.), a herb used in beer production, contains flavonoids in the form of flavonol glycosides, such as prenylflavonoids and procyanidins ${ }^{14)}$. Procyanidins from hops pomace are mainly composed of various catechin oligomers ${ }^{15)}$. Procyanidins exhibit various biological activities. For instance, procyanidins from grape seed stimulate glucose uptake in insulin-resistant adipocytes ${ }^{16)}$, whereas oligomeric procyanidins from lychee fruit stones exhibit antioxidant activities in vitro ${ }^{17)}$. A major component of hop procyanidins has a higher molecular weight than these known procyanidins. Inhibitory effects of dietary intake of hop pomace polyphenols on gastric injury due to Helicobactor pylori VacA toxin ${ }^{18)}$ and prevention of dental plaque formation ${ }^{19)}$ have been previously reported. Stevens et $a l .^{20)}$ reported the biological properties of hop procyanidins in vitro: inhibition of neuronal nitric oxide synthase activity and scavenging of reactive nitrogen species.

\footnotetext{
*Correspondence to: Kyoichi Osada, Department of Agricultural Chemistry, School of Agriculture, Meiji University, 1-1-1 Higashimita, Tama-ku, Kawasaki, Kanagawa 214-8571, JAPAN

E-mail: kyochi@isc.meiji.ac.jp

Accepted December 15, 2012 (received for review November 22, 2012)

Journal of Oleo Science ISSN 1345-8957 print / ISSN 1347-3352 online

http://www.jstage.jst.go.jp/browse/jos/ http://mc.manusriptcentral.com/jjocs
} 
However, the biological activities of dietary high-molecularweight procyanidins, including their anti-obesity effects, have not yet been elucidated because their intestinal absorption is not yet understood.

In this study, we examined the effect of a high dose of dietary hop pomace polyphenols on growth parameters, hepatic fatty acid metabolism, and diabetic parameters in Otsuka Long-EvansTokushima Fatty (OLETF) rats, which is an animal model of type 2 diabetes.

\section{EXPERIMENTAL PROCEDURES}

\subsection{Reagents}

Purified hop pomace polyphenols (HPs) were obtained from Asahi Brewery Co., Ltd. (Tokyo, Japan). HPs consist of approximately $60 \%$ of procyanidins (which contain (-) -epicatechins of more than 8-mer), 15\% other flavonoids, $3 \%$ astragalin, $2 \%$ isoquercitrin, and $20 \%$ unknown phenolic constituents. Mouse anti-fatty acid synthase (FAS), goat anti-glucose-6-phosphate dehydrogenase (G6PDH, Leuconostoc mesenteroides), and mouse anti- $\beta$-actin antibodies, as well as goat anti-mouse IgG-horseradish peroxidase (HRP) and bovine anti-goat IgG-HRP, also were purchased from Santa Cruz Biotechnology, Inc., CA, USA. Mouse anti-malic enzyme(ME) 1 monoclonal antibody was purchased from Abnova Co. (Taipei, Taiwan).

\subsection{Animals and Diets}

All animal experiments were conducted according to the guidelines provided by the ethical committee of experimental animal care at Meiji University (approval code: IACUC10-0008).

OLETF and Long-Evans Tokushima (LETO) rats (4-weekold males: Otsuka Pharmaceutical, Tokushima, Japan)were housed individually in a temperature- $\left(22^{\circ} \mathrm{C}-24^{\circ} \mathrm{C}\right)$ and light-controlled (0700 - 1900) room. After a 1-week-acclimatization period, 14 OLETF rats were divided into 2 groups: one group ( 7 rats) was fed a control diet (C-group; $2 \%$ lard and 5\% high oleic safflower oil), and the other group ( 7 rats) was fed control diet supplemented with $1 \%$ HPs (H-group). Additionally, 6 LETO rats were given the control diet(NC-group). Diets were prepared according to AIN93G recommendations ${ }^{21)}$; detailed diet compositions are shown in Table 1. Rats were pair-fed by measuring daily food consumption because dietary polyphenols sometimes caused a slight reduction in food intake and food consumption in NC-group was considarbly higher than that in the other 2 groups in first period (until 21 days). Rats were given free access to each of the diets for latter 39 days.

After 70 days, rats were anesthetized using diethyl ether and bled from the abdominal aorta; various tissues were then quickly excised. Plasma was prepared by centrifuga-
Table 1 Diet composition.

\begin{tabular}{lccc}
\hline \multicolumn{1}{c}{ Component } & NC & Croup & H \\
\hline & \multicolumn{3}{c}{ Weight \% } \\
Cornstarch & 36.8 & 36.8 & 35.8 \\
Casein & 20 & 20 & 20 \\
Pregelatinized cornstarch & 13.2 & 13.2 & 13.2 \\
Sucrose & 13 & 13 & 13 \\
High oleic safflower oil & 5 & 5 & 5 \\
Lard & 2 & 2 & 2 \\
Cellulose & 5 & 5 & 5 \\
Mineral mix (AIN93G) & 3.5 & 3.5 & 3.5 \\
Vitamin mix (AIN93) & 1 & 1 & 1 \\
L-Cystine & 0.3 & 0.3 & 0.3 \\
Choline bitartrate & 0.2 & 0.2 & 0.2 \\
HP & 0 & 0 & 1 \\
\hline
\end{tabular}

$\mathrm{HP}$, procyanidins rich polyphenol from hop pomace, NC, LETO rats fed diet without HP; C, OLETF rats fed diet without HP; H, OLETF rats fed diet with HP.

tion after allowing blood to clot at room temperature. These samples were kept at $-80^{\circ} \mathrm{C}$ until required for analyses.

\subsection{Plasma and liver lipid analyses}

The levels of plasma triglycerides, total cholesterol, and high-density lipoprotein (HDL)-cholesterol were measured using commercial kits (Wako Pure Chemical Industries, Ltd, Osaka, Japan) after the rats were killed. Liver lipids were extracted by the method described by Folch et $a l .{ }^{22)}$. The levels of liver triglycerides, cholesterol, and phospholipids were measured as described by Ide $e t a l .^{23)}$, Burchard et $a l^{24)}$, and Rouser et $a l .{ }^{25)}$, respectively.

\subsection{Plasma levels of glucose, $\mathrm{HbA} 1 \mathrm{c}$, and insulin}

After 40 days, all rats were fasted overnight with ad libitum access to water. The following morning, blood was collected from their tail veins. Plasma was prepared as described above. Plasma levels of glucose (Glucose CII-Test Wako; Wako Pure Chemical Industries, Ltd, Osaka, Japan) and $\mathrm{HbA1c}$ were measured using commercial kits (RAPIDIA Auto HbA1c-L; FUJIREBIO Inc., Tokyo, Japan). Plasma insulin levels were measured after 70 days by using a Mercodia Rat Insulin ELISA Kit(Mercodia, Uppsala, Sweden).

\subsection{Preparation of liver mitochondria/peroxisomes}

After sacrifice, a section of liver (approximately $3 \mathrm{~g}$ ) was homogenized in 7 volumes of ice-cold $0.25 \mathrm{M}$ sucrose homogenizing solution containing $1 \mathrm{mM}$ ethylenediaminetetraacetic acid (EDTA) and $3 \mathrm{mM}$ Tris- $\mathrm{HCl}(\mathrm{pH} \mathrm{7.2)}$. The ho- 
mogenate was centrifuged at $500 \times g$ for $10 \mathrm{~min}$ at $4^{\circ} \mathrm{C}$. The supernatant was again centrifuged at $9000 \times g$ for $10 \mathrm{~min}$ at $4^{\circ} \mathrm{C}$ to isolate mitochondria. Mitochondria were washed twice with the homogenizing solution and finally resuspended in $3 \mathrm{~mL}$ of this solution. The supernatant from the $9000 \times g$ centrifugation step was centrifuged at $105000 \times g$ for $60 \mathrm{~min}$ at $4^{\circ} \mathrm{C}$ to obtain a pellet containing microsomes; the supernatant from this step represented the cytosolic fraction.

\subsection{Enzyme activity assay}

Fatty acid synthase (FAS) activity was determined spectrometrically by the method of Nepokroeff et al. ${ }^{26)}$ in $0.2 \mathrm{M}$ potassium phosphate buffer ( $\mathrm{pH} 7.0$ ) containing $0.4 \mathrm{mM}$ EDTA, $200 \mu \mathrm{M}$ malonyl-CoA, $50 \mu \mathrm{M}$ acetyl-CoA, $300 \mu \mathrm{M}$ $\mathrm{NADPH}$, and the sample suspension(i.e., the supernatant acquired in the $9000 \times g$ centrifugation step). One unit of FAS was defined as the amount of enzyme required to synthesize $1 \mathrm{nmol}$ palmitic acid (equivalent to the oxidation of $14 \mathrm{nmol}$ of NADPH) per minute at $30^{\circ} \mathrm{C}$.

G6PDH activity was measured as previously described ${ }^{27)}$. The reaction mixture ( $\mathrm{pH} 7.6$ ) contained $0.1 \mathrm{M}$ Tris-HCl, 30 mM MgCl $2,3.3$ mM glucose-6-phosphate, 1.2 mM NADP, 0.5 unit/mL 6-phosphogluconate dehydrogenase, and sample suspension (i.e., the supernatant acquired in the $105000 \times$ $g$ centrifugation step). One unit of G6PDH activity was expressed as production of $1 \mathrm{nmol}$ NADPH per minute.

ME activity was measured as described by Pongratz et $a l .{ }^{28)}$. The reaction mixture ( $\left.\mathrm{pH} 7.4\right)$ contained $1.5 \mathrm{M}$ Tris$\mathrm{HCl}, 0.12 \mathrm{M} \mathrm{MgCl}_{2}, 0.03 \mathrm{M}_{\mathrm{L}}$-malate, $3.4 \mathrm{mM} \mathrm{NADP}$, and sample suspension (i.e., the supernatant acquired in the $105000 \times g$ centrifugation step). One unit of malic enzyme was defined as the amount of enzyme that yielded $1 \mathrm{nmol}$ of NADPH per minute.

Peroxisomal acyl-CoA oxidase (ACOX) activity was assayed by measuring palmitoyl-CoA-dependent $\mathrm{H}_{2} \mathrm{O}_{2}$ production, as described by Hashimoto et al. ${ }^{29)}$. The reaction mixture contained $58 \mathrm{mM}$ potassium phosphate ( $\mathrm{pH} 7.4$ ), $10.6 \mathrm{mM}$ phenol, $0.82 \mathrm{mM}$ 4-aminoantipyrine, $10 \mathrm{mM} \mathrm{FAD}$, $4 \mathrm{U}$ horse radish peroxidase, $0.1 \mathrm{mM}$ palmitoyl-CoA, 0.2 $\mathrm{mg} / \mathrm{mL}$ of albumin, and the enzyme solution (i.e., the supernatant acquired in the $500 \times g$ centrifugation step).

Carnitine palmitoyltransferase II (CPTII) activity was measured by determining the 5-thio-2-nitrobenzoate (TNB) production following the method of Markwell et $a l .{ }^{30)}$. The reaction mixture contained $116 \mathrm{mM}$ Tris- $\mathrm{HCl}$ buffer (pH 8.0), 2.5 mM EDTA, $5 \mu \mathrm{M} 5,5^{\prime}$-dithiobis-(-2-nitrobenzoic acid) (DTNB), 0.2\% Triton-X100, $1.25 \mathrm{mM} \mathrm{L}-$ carnitine, $2 \mathrm{mM}$ palmitoyl-CoA, and the enzyme solution (mitochondria fraction: the suspended solution of sediment acquired in the $9000 \times g$ centrifugation step).

\subsection{Western blot analysis}

The levels of enzymes involved in fatty acid synthesis in liver were analyzed by western blotting. Tissue lysates from liver were prepared by lysis using the CelLytic ${ }^{\mathrm{TM}} \mathrm{MT}$ mammalian tissue lysis/extraction reagent (Sigma Chemicals, St. Louis, MO, USA). Protein concentrations were measured using a protein assay kit(Bio-Rad Laboratories Co. Ltd., Hercules, CA, USA). Protein extracts were separated by $10 \%$ SDS-PAGE and transferred to a polyvinylidene difluoride membrane, which was then blocked in buffer containing $0.2 \%$ casein in phosphate-buffered saline containing $0.1 \%$ Tween 20 for $1 \mathrm{~h}$. These membranes were then incubated with a mouse anti-FAS (1:1000 v/v dilution), goat anti-G6PDH(1:2000 v/v dilution), mouse anti-ME1 $(1: 500 \mathrm{v} / \mathrm{v}$ dilution $)$, or mouse anti- $\beta$-actin $(1: 1000 \mathrm{v} / \mathrm{v}$ dilution) antibody for $1 \mathrm{~h}$ at $25^{\circ} \mathrm{C}$. The membranes were subsequently washed with the blocking solution and incubated with a secondary antibody (FAS, ME, and $\beta$-actin: goat antimouse IgG-HRP, 1:1000 v/v dilution; G6PDH: bovine antigoat IgG-HRP, 1:2000 v/v dilution) for $1 \mathrm{~h}$ at $25^{\circ} \mathrm{C}$.

After washing with the blocking solution, the signal was detected using ECL Western Blotting Substrate(Promega, CO, Fitchburg, WI, USA). The signal of each enzyme was analyzed using the ChemiDoc-It 410 Imaging System(UltraViolet Products, Ltd., Cambridge, United Kingdom), and the intensity of each signal standardized to the signal of $\beta$-actin. The fold-increase or fold-decrease for each protein was determined as compared to the relevant intensity in the NC-group (set equal to 1).

\subsection{RNA extraction}

Total RNA was extracted from rat liver tissue using RNAiso Plus (Takara Bio Inc., Kyoto, Japan). RNA concentration was determined by measuring the absorbance at $260 \mathrm{~nm}$ by ultraviolet photometer. RNA samples were treated by DNase(RQ1 RNase-Free DNase: Promega Co., Fitchburg, WI, USA) and after phenol-chloroform extraction, purified RNA sample aliquots were stored at $-80^{\circ} \mathrm{C}$.

\subsection{Oligonucleotide primer sequences}

The primers for reverse transcription polymerase chain reaction (RT-PCR) amplification of the rat $S R E B P 1 C$ gene, primers were designed using Primer3Plus software (http:// www.bioinformatics.nl/cgi-bin/primer3plus/primer3plus. cgi). The primers, synthesized by Operon Biotechnologies (Tokyo, Japan), were designed to flank known or putative introns of this gene, thereby preventing amplification of any contaminating genomic DNA. The primer sequences were as follows: $\operatorname{SREBP1C}$ (Gene ID:78968) forward: 5' -GGAGCCATGGATTGCACATT-3' and reverse: 5' -AGGAAGGCTTCCAGAGAGGA-3' . The gene encoding glyceraldehyde 3-phosphate dehydrogenase (GAPDH, Gene ID: 24383, forward: 5' -CTCATGACCACAGTCCATGC-3' ; reverse: $5^{\prime}$-TTCAGCTCTGGGATGACCTT-3' ) was used as control. 


\subsection{Real-time quantitative polymerase chain reaction}

One microgram of RNA sample was incubated at $65^{\circ} \mathrm{C}$ for $5 \mathrm{~min}$ and quickly cooled on ice. Reverse transcription of RNA was performed by heating the sample to $37^{\circ} \mathrm{C}$ for 15 min and heating at $98^{\circ} \mathrm{C}$ for 5 min using a ReverTra ${ }^{\oplus}$ Ace qPCR RT kit(Toyobo Co., LTD, Osaka, Japan). An aliquot of the generated cDNA samples was mixed with 5 $\mu \mathrm{L}$ of THUNDERBIRD ${ }^{\mathrm{TM}}$ SYBR $^{\circledR}$ qPCR Mix (Toyobo Co., Ltd., Osaka, Japan) in the presence of $0.3 \mu \mathrm{mol}$ of each of the forward and reverse primers for GAPDH and SREBP1C. This reaction mixture was then subjected to the following cycling conditions in a Chromo 4 Sequence Detection System (Bio-Rad Laboratories, Inc. Hercules, CA, USA) : 1 cycle at $95^{\circ} \mathrm{C}$ for $1 \mathrm{~min}$ followed by 40 cycles of $95^{\circ} \mathrm{C}$ for 15 $\mathrm{s}$ and $58.5^{\circ} \mathrm{C}$ for $1 \mathrm{~min}$. The results (fold-changes) were expressed as relative fold-changes by comparing the amount of RNA of the target gene to that of the $G A P D H$ gene as an internal control, as determined by the equation $2^{-\mathrm{C}(t) \text { target }-\mathrm{C}(\mathrm{t}) \mathrm{GAPDH}}$.

\subsection{Statistical analysis}

Data are expressed as means $\pm \mathrm{SE}$. The statistical analysis of data was performed using one-way analysis of variance and the Tukey-Kramer test to evaluate significant differences between a pair of means. Differences were considered significant at $p<0.05$.

\section{RESULTS}

\subsection{Effects of dietary hop pomace polyphenols on growth parameters}

The final body weight was higher in the OLETF rats (C and H-group) than in the LETO rats (NC-group, Table 2); however, dietary HPs tended to reduce the final body weight in OLETF rats $(p=0.077)$. Although dietary HPs modulated weight gain in OLETF rats, there was no significant difference in the weight gain between the NC-group and the C-group.

The final abdominal circumference in the OLETF rats was significantly higher than that of the NC-group; however, it was lower in the H-group than in the C-group. The liver weight in H-group tended to be lower than that in C-group. The weight of total white adipose tissues was significantly higher in both OLETF rat groups than in the LETO rat group, although it was lower in the H-group than that in the C-group. Dietary HPs significantly reduced the increase in weight of the mesenteric white adipose tissue in OLETF rats. The weight of perirenal and abdominal subcutaneous white adipose tissues also were lower in the $\mathrm{H}$-group than in C-group, although these differences were not significant.

\subsection{Effects of dietary hops pomace polyphenols on plas- ma and liver lipid levels}

Plasma triglyceride levels were higher in the C-group than in the NC-group; however, the levels tended to be

Table 2 Effects of dietary HP on growth parameter.

\begin{tabular}{|c|c|c|c|}
\hline & \multicolumn{3}{|c|}{ Group } \\
\hline & $\mathrm{NC}$ & $\mathrm{C}$ & $\mathrm{H}$ \\
\hline \multicolumn{4}{|l|}{ Growth parameter } \\
\hline Initial body weight (g) & $84 \pm 3^{\mathrm{a}}$ & $108 \pm 3^{\mathrm{b}}$ & $108 \pm 2^{\mathrm{b}}$ \\
\hline Final body weight (g) & $349 \pm 7^{\mathrm{a}}$ & $369 \pm 5^{\mathrm{b}}$ & $353 \pm 4 a^{b}$ \\
\hline Weight gain (g) & $264 \pm 7^{\mathrm{a}}$ & $261 \pm 3^{\mathrm{ab}}$ & $245 \pm 2^{\mathrm{b}}$ \\
\hline Food intake (g/70day) & $1230 \pm 8$ & $1231 \pm 2$ & $1230 \pm 1$ \\
\hline Liver weight (g) & $11.8 \pm 0.4^{\mathrm{a}}$ & $10.0 \pm 0.4^{\mathrm{b}}$ & $9.3 \pm 0.2^{b}$ \\
\hline Initial waist $(\mathrm{cm})$ & $10.4 \pm 0.2^{\mathrm{a}}$ & $11.5 \pm 0.2^{\mathrm{b}}$ & $11.1 \pm 0.2^{\mathrm{ab}}$ \\
\hline Final waist $(\mathrm{cm})$ & $15.1 \pm 0.1^{\mathrm{a}}$ & $16.5 \pm 0.2^{\mathrm{b}}$ & $15.7 \pm 0.2^{\mathrm{c}}$ \\
\hline Waist gain $(\mathrm{cm})$ & $4.7 \pm 0.2$ & $4.9 \pm 0.4$ & $4.7 \pm 0.1$ \\
\hline \multicolumn{4}{|c|}{ White adipose tissues (WAT) weight (g) } \\
\hline Epididymal WAT & $6.48 \pm 0.48^{\mathrm{a}}$ & $8.23 \pm 0.64^{\mathrm{b}}$ & $8.60 \pm 0.43^{\mathrm{b}}$ \\
\hline Perirenal WAT & $6.62 \pm 0.56^{\mathrm{a}}$ & $13.2 \pm 0.4^{\mathrm{b}}$ & $11.9 \pm 0.4^{\mathrm{b}}$ \\
\hline Mesenteric WAT & $1.92 \pm 0.14^{\mathrm{a}}$ & $5.23 \pm 0.15^{\mathrm{b}}$ & $3.78 \pm 0.31^{\mathrm{c}}$ \\
\hline Abdominal subcutaneous WAT & $4.62 \pm 0.53^{\mathrm{a}}$ & $15.80 \pm 2.22^{\mathrm{b}}$ & $15.42 \pm 0.79^{b}$ \\
\hline Total WAT & $19.63 \pm 1.52^{\mathrm{a}}$ & $42.43 \pm 3.15^{\mathrm{b}}$ & $39.75 \pm 1.28^{\mathrm{b}}$ \\
\hline
\end{tabular}

Data are presented as mean \pm SE of $6-7$ rats in each group.

${ }^{\text {abc }}$ Value without a common superscript letter are significantly different at $p<0.05$. 
lower in the H-group than in the C-group (Table 3). Plasma cholesterol levels were the highest in the C-group, whereas they were the lowest in the H-group. Moreover, HDL-cholesterol levels in both $\mathrm{C}$ - and H-groups were significantly lower than those in the NC-group. The arteriosclerotic index of the C-group was higher than that in the NC-group; however, there was no difference in this index between the $\mathrm{H}$ - and NC-groups. Dietary HPs lowered the liver triglyceride level in the H-group compared to the C-group, and was similar to that in the NC-group. There were, however, no significant differences in liver cholesterol or phospholipids levels among the 3 groups, although phospholipids levels in the H-group were slightly, but not significantly, higher than those in the C-group.

\subsection{Effects of dietary hop pomace polyphenols on fasting blood glucose, $\mathrm{HbA1c}$, and insulin levels}

At 40 days, both fasting blood glucose and HbA1c levels were significantly higher in the C-group than in the NC-group (Fig. 1). However, dietary HPs significantly lowered both fasting blood glucose and HbA1c levels in OLETF rats; these were similar to the levels in the NCgroup. Furthermore the plasma insulin levels in both the Cand H-groups were lowered compared to the NC-group at 70 days.

\subsection{Effects of dietary hop pomace polyphenols on plasma adiponectin, MCP-1, and leptin levels}

Plasma adiponectin and leptin levels were similar in the C- and H-groups, which were higher than in the NC-group

Table 3 Effects of dietary HP on plasma and liver lipid levels.

\begin{tabular}{lccc}
\hline & \multicolumn{3}{c}{ Group } \\
\hline & $\mathrm{NC}$ & $\mathrm{C}$ & $\mathrm{H}$ \\
\hline Plasma & & & \\
Triglyceride (mg/dl) & $65.5 \pm 9.7$ & $69.5 \pm 3.6$ & $58.2 \pm 3.0$ \\
Cholesterol (mg/dl) & $176.3 \pm 11.5$ & $191.3 \pm 23.7$ & $153.7 \pm 7.3$ \\
HDL-cholesterol (mg/dl) & $64.3 \pm 5.0^{\mathrm{a}}$ & $46.8 \pm 3.0^{\mathrm{b}}$ & $51.7 \pm 1.8^{\mathrm{b}}$ \\
Arteriosclerotic index & $1.8 \pm 0.3$ & $3.2 \pm 0.8$ & $2.0 \pm 0.2$ \\
\hline Liver & & & \\
Triglyceride (mg/g) & $16.5 \pm 3.1$ & $21.1 \pm 1.4$ & $17.0 \pm 1.2$ \\
Cholesterol (mg/g) & $4.1 \pm 0.1$ & $4.0 \pm 0.1$ & $4.2 \pm 0.2$ \\
Phospholipids (mg/g) & $31.3 \pm 0.9$ & $36.1 \pm 1.1$ & $40.0 \pm 0.6$ \\
\hline
\end{tabular}

Data are presented as mean \pm SE of 6-7 rats in each group.

${ }^{\mathrm{ab}}$ Value without a common superscript letter are significantly different at $p<0.05$.
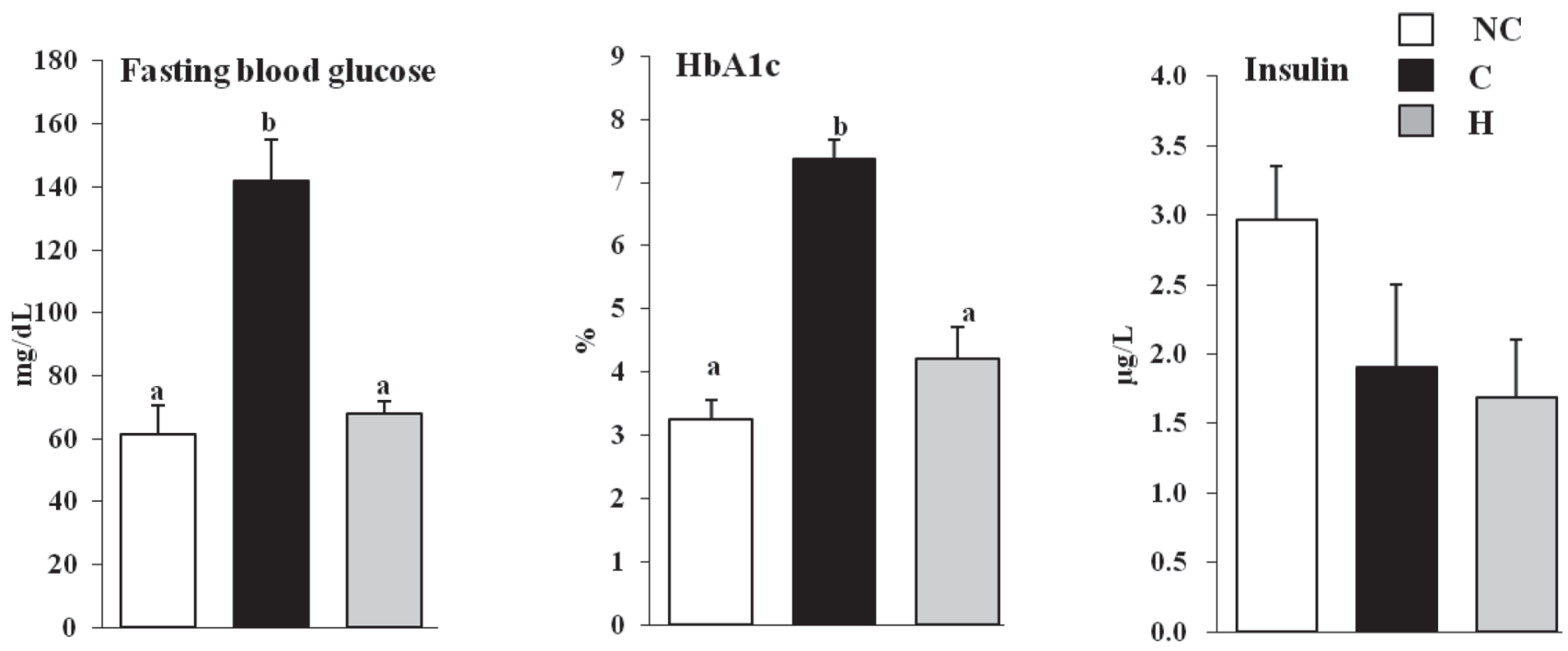

Fig. 1 Effect of dietary hop polyphenol on fasting blood glucose, HbA1c, and insulin levels. Data are given as the mean \pm SE for 6-7 rats. ${ }^{\text {ab }}$ Different letters indicate significantly different values, with $p<0.05$. 
(Fig. 2). In contrast, the plasma MCP-1 level was the lowest in the H-group.

\subsection{Effects of dietary hop pomace polyphenols on hepatic fatty acid synthesis activity}

The activities of hepatic lipogenic enzymes, viz. FAS, $\mathrm{G} 6 \mathrm{PDH}$, and $\mathrm{ME}$, were significantly higher in the C-group than in the NC-group; however, dietary HPs significantly lowered the activities of these enzymes in OLETF rats (Fig. $3)$. The activities of enzymes involved in fatty acid $\beta$-oxidation, viz. ACOX and CPT-II, were not significantly different among the groups, although the ACOX activity was the lowest and CPT-II activity was the highest in the H-group.

\subsection{Effect of dietary hop pomace polyphenols on proteins levels of hepatic lipogenic enzymes}

The protein levels of the hepatic lipogenic enzymes, viz. FAS, G6PDH, and ME, tended to be higher in the C-group than in the NC-group but they tended to be lower in the H-group than in the C-group (Fig. 4).

\subsection{Effect of dietary hop pomace polyphenols on expres- sion of SREBP1C}

The hepatic expression of $S R E B P 1 c$ was higher in the C-group than in the NC-group, although this difference was not statistically significant (Fig. 5). However, the hepatic expression of SREBP1C in OLETF rats was significantly reduced by dietary HP.

\section{DISCUSSION}

We examined the effect of a high dose of dietary HPs on growth parameters in OLETF rats, an animal model of obesity and type 2 diabetes. Dietary HPs tended to reduce the final body weight and liver weight in OLETF rats. The weight of mesenteric white adipose tissue in OLETF rats was significantly lowered by dietary HPs; however, the weight of total white adipose tissues tended to be lower in the H-group than in the C-group. Thus, intake of dietary HPs decreases the tissue weight and the fat weight. The weights of organs other than the liver and other subcutaneous white adipose tissues may be lower in the H-group than in the C-group. Therefore, more detailed studies will be needed to evaluate more precisely the anti-obesity effect of dietary HPs.

Dietary hesperidin and naringin have been shown to suppress plasma and liver triglyceride levels in $o b / o b$ mice $^{311}$. Black tea catechins are also known to significantly reduce triglyceride levels and gain in body weight. Thus, various dietary polyphenols exhibit an anti-obesity effect by reducing triglyceride levels ${ }^{32}$. Dietary HPs also lowered plasma and liver triglyceride levels in OLETF rats, although these effects were not significant. Reexamination will be necessary to evaluate these effects by increasing the number of animals or changing the dose level of HPs in the subsequent study.

FAS, G6PDH, and ME are enzymes involved in fatty acid synthesis in liver. Dietary HPs significantly suppressed the activities of these enzymes in OLETF rats. Sterol regulatory element-binding proteins (SREBPs) are key transcription factors that are associated with lipogenesis, adipocyte development $^{33)}$, and cholesterol homeostasis ${ }^{34,35)}$. SREBP1c regulates genes that are important for lipid metabolism, including those regulating fatty acid synthesis. Dietary HPs significantly reduced the hepatic expression of SREBP $1 c$ in OLETF rats, suggesting that a part of the HPs was absorbed from the small intestine and that its metabolites inhibit the synthesis of fatty acids in the liver. These effects may contribute to the decreased liver weight and liver triglyceride level in the H-group, although it was not signifi-
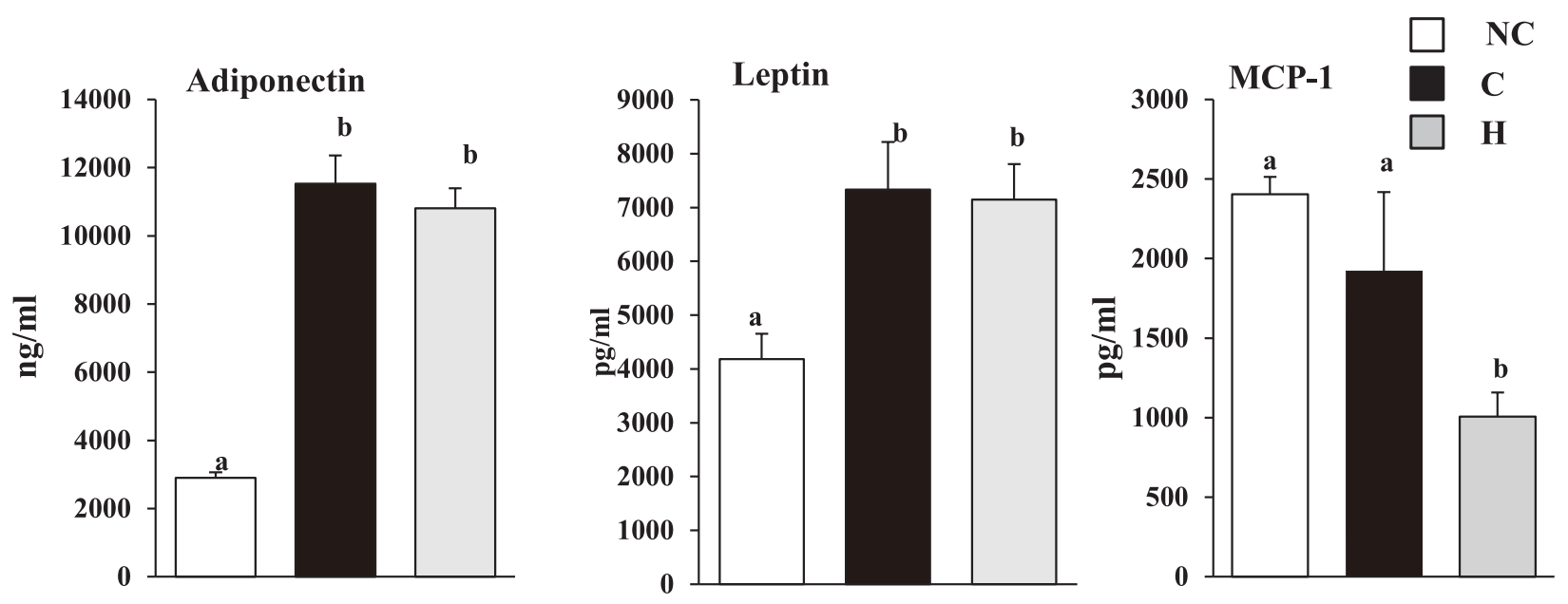

Fig. 2 Effect of dietary hop pomace polyphenols on plasma adiponectin, leptin, and MCP-1 levels. Data are given as mean \pm SE of 6-7 rats. ${ }^{\text {ab }}$ Different letters indicate significantly different values, with $p<0.05$. 


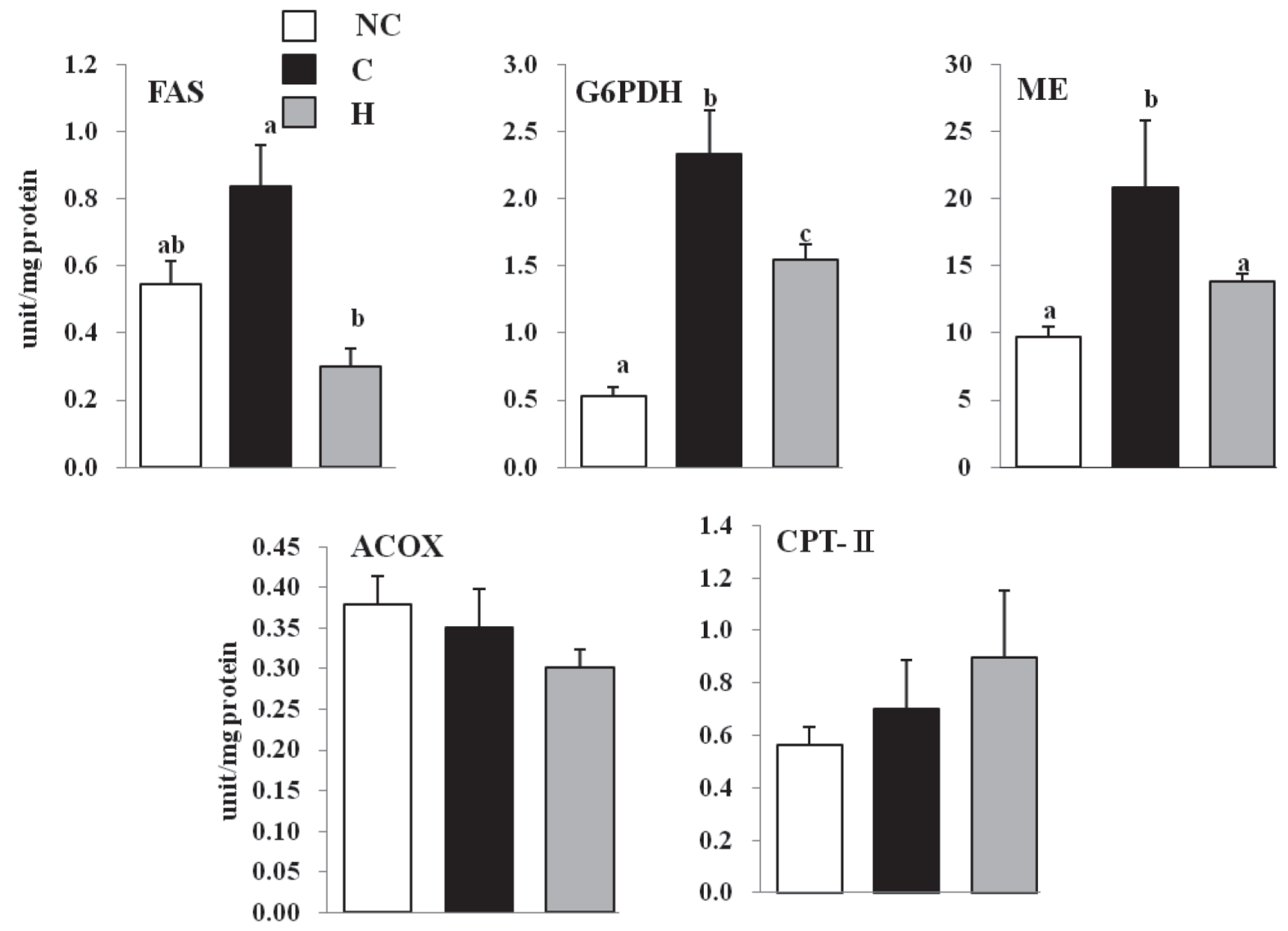

Fig. 3 Effect of dietary hop pomace polyphenols on enzyme activities of fatty acid synthesis and $\beta$-oxidation in liver. Data are given as mean \pm SE of 6-7 rats. ${ }^{\text {ab }}$ Different letters indicate significantly different values, with $p<0.05$.
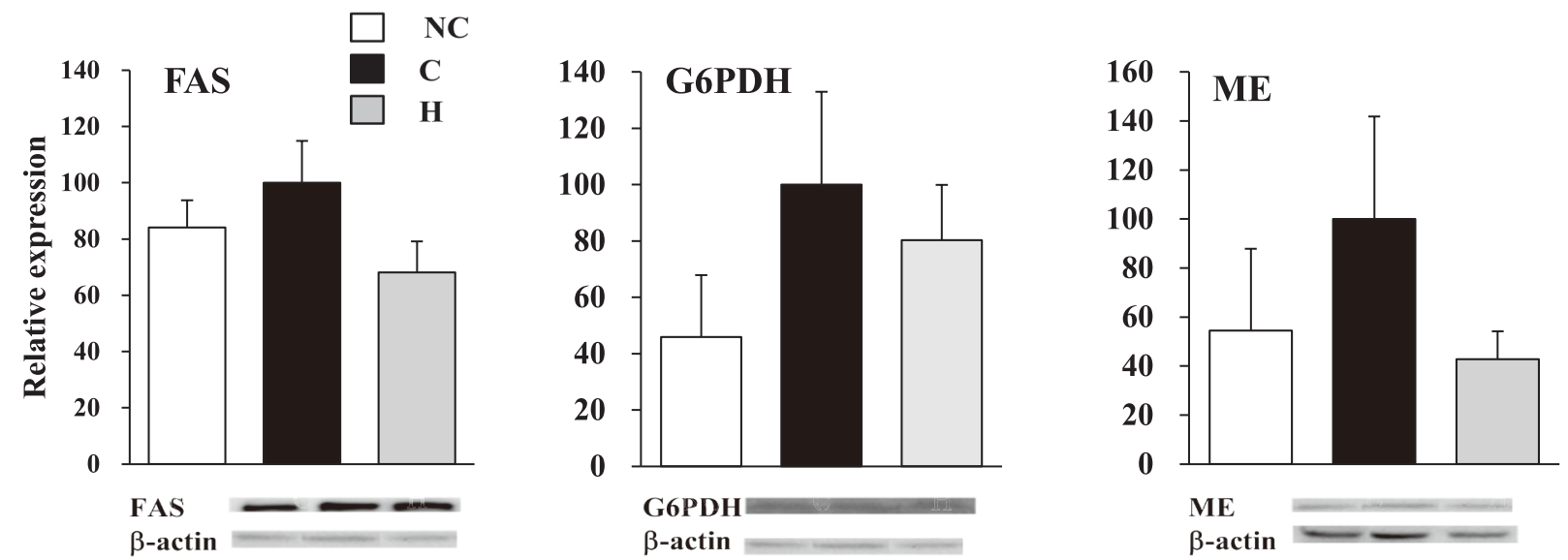

Fig. 4 Effect of dietary hop pomace polyphenols on protein levels of enzymes involved in fatty acid synthesis in liver. Data are given as the mean \pm SE for 6-7 rats. FAS, fatty acid synthase; G6PDH, glucose-6-phosphate dehydrogenase; ME, malic enzyme; ACOX, acyl-CoA oxidase; CPT II, carnitine palmitoyltransferase II.

cant effect.

It is well known that high-molecular-weight procyanidins, which are the main component of HPs, are rarely absorbed via the small intestine. However, tea catechins, or low-molecular-weight procyanidins, are indeed absorbed in humans and other animals. Moreover, apple procyanidins, consisting of catechin oligomers that range from dimers to pentamers, are absorbed in rats ${ }^{36)}$. Therefore, fatty acid metabolism in liver may be regulated by metabolites of lowmolecular-weight procyanidins or monomeric polyphenols 


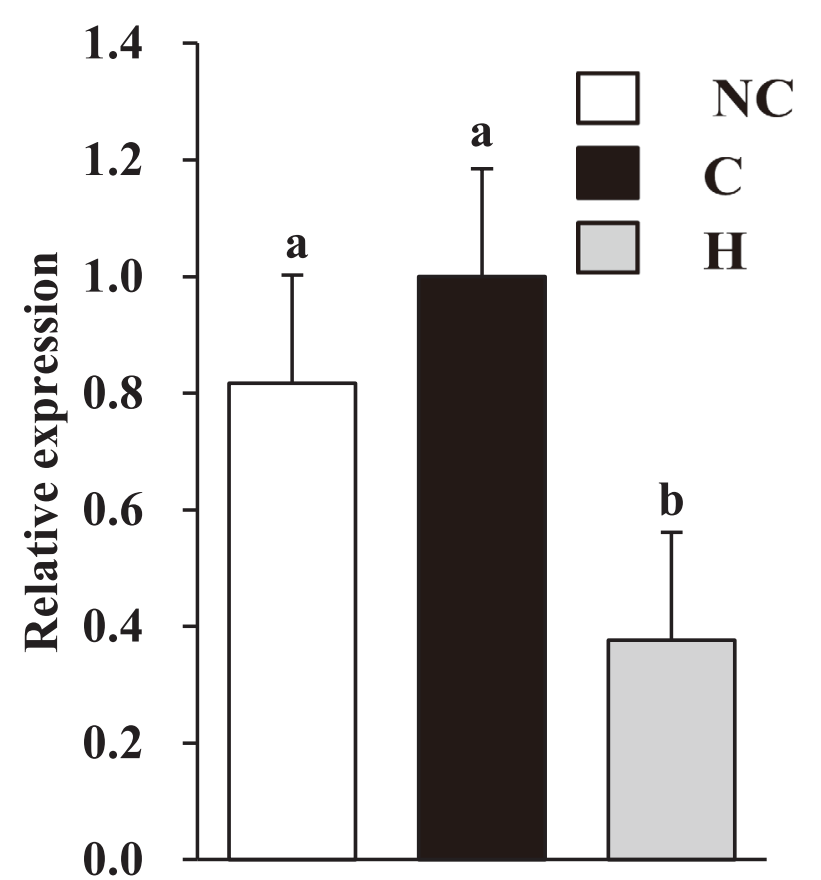

Fig. 5 Effect of dietary hop pomace polyphenol on expression of the sterol regulatory element-binding protein1c (SREBP1c) gene in liver. Data are given as mean $\pm \mathrm{SE}$ for $6-7$ rats. ${ }^{\text {ab }}$ Different letters indicate significantly different values, with $p<0.05$.

in HPs absorbed from the small intestine, although we do not have a concrete explanation now.

Qiang et al. reported that tea catechins inhibit pancreatic lipase activity in vitro ${ }^{37)}$. HPs inhibited the activity of a pancreatic lipase in our in vitro experiment (the half maximal inhibitory concentration[ $\left[\mathrm{IC}_{50}\right]$ of HPs was $2.5 \mathrm{mg} /$ $\mathrm{ml}$ ). Dietary apple polyphenols, especially high-molecularweight procyanidins, may inhibit the intestinal absorption of lipids through micellar disruption ${ }^{38}$. The excreted feces level in the H-group was the highest among the 2 study groups (NC-group: $2.75 \pm 0.11 \mathrm{~g} /$ day; C-group: $2.86+0.06 \mathrm{~g} /$ day; H-group: $3.19+0.05 \mathrm{~g} /$ day). The same result was observed for the excreted triglyceride level in feces (NCgroup: $1.05 \pm 0.11 \mathrm{mg} /$ day; C-group: $1.45+0.12 \mathrm{mg} /$ day; H-group: $1.66+0.12 \mathrm{mg} /$ day). Therefore, dietary HPs may exhibit an anti-obesity effect in OLETF rats through both the regulation of fatty acid metabolism and the inhibition of dietary lipids absorption from the small intestine.

Dietary HPs significantly reduced the fasting blood glucose and HbA1c levels in OLETF rats at 40 days. It has been reported that consumption of green tea polyphenols lowered insulin and blood glucose levels in male Wistar rats fed a high-fructose diet ${ }^{39}$. However, dietary HP did not improve the insulin levels in our study; this may be because of the pair-feeding condition and the short duration of this study. In addition, an insulin-enhancing function of dietary polyphenols has been reported in tea catechins ${ }^{40)}$. In our supplemental experiment, the administration of HPs $(200 \mathrm{mg} / \mathrm{kg}$ body weight) modulated the oral glucose tolerance over a period of $120 \mathrm{~min}$ of an oral glucose tolerance test (OGTT) in 6-weeks-old male Wistar rats $(\mathrm{n}=4)$ after glucose load of $2 \mathrm{~g} / \mathrm{kg}$ body weight (area under the curve of blood glucose levels obtained from the OGTT: C-group: $13011 \pm 607 \mathrm{mg} \cdot \mathrm{min} / \mathrm{dL} ; \mathrm{H}$-group: $12178 \pm 373 \mathrm{mg} \cdot \mathrm{min} / \mathrm{dL}$; $p<0.05)$. Therefore, the metabolites from HPs may well enhance insulin functioning. An insulin tolerance test also must be examined in future studies.

Pancreatic and intestinal glucosidases are the key enzymes involved in dietary carbohydrate digestion. In order to moderate hyperglycemia, inhibitors of the activities of these enzymes must be effective in reducing glucose absorption from the intestine. Theaflavins in black tea possess a potent antihyperglycemic function ${ }^{41}$; the mechanism involves the delay or inhibition of glucose production in the small intestine by inhibiting of $\alpha$-glucosidase activity. The same effects were observed for green tea polyphenols and procyanidins from French maritime pine bark extract (pycnogenol) ${ }^{42,43)}$. Angelika et al. also previously reported that the inhibitory effect of pycnogenol on $\alpha$-glucosidase activity increased depending on the degree of polymerization of procyanidins ${ }^{43}$. HPs also inhibited various enzyme activities related to carbohydrate digestion in our in vitro experiment $\left(\mathrm{IC}_{50}\right.$ of $\alpha$-amylase: $2 \mathrm{mg} / \mathrm{ml}$; $\mathrm{IC}_{50}$ of sucrase: 4 $\mathrm{mg} / \mathrm{mL}$; $\mathrm{IC}_{50}$ of maltase: $1 \mathrm{mg} / \mathrm{mL} ; \mathrm{IC}_{50}$ of isomaltase: $3 \mathrm{mg} /$ $\mathrm{mL}$ ). The level of excreted carbohydrate in the feces of the $\mathrm{H}$-group also was 1.2-times higher than that in the Cgroup. Thus, dietary HPs may exert antihyperglycemic effects through inhibitory action on carbohydrate digestion. However, studies about effect of short chain fatty acids from undigested carbohydrate also need to be studies because they reduce lipogenesis in liver.

Adipocytes have recently been shown to be dynamic endocrine cells that produce various bioactive molecules, adipokines, some of which affect insulin sensitivity; these include TNF- $\alpha$, leptin, and adiponectin. The expression of MCP-1, another adipokine, is increased in obesity. MCP-1 is produced predominantly by macrophages and endothelial cells, and it is a potent chemotactic factor for monocytes. Gu et al. suggested that MCP-1 plays an important role in atherogenesis $^{44)}$. In addition, MCP-1 is a link between obesity and insulin resistance through induction of an inflammatory response in adipose tissue ${ }^{45)}$. In this study, dietary HPs significantly lowered plasma levels of MCP-1 in OLETF rats. Therefore, various inflammatory responses accompanying the increase of the adipose tissue mass may be ameliorated by dietary HPs. 


\section{CONCLUSION}

We found that dietary HPs inhibited the increase of body weight and white adipose tissues mass in OLETF rats, although these effects were not significant. Dietary HPs also reduced the hepatic expression of $S R E B P 1 C$ and suppressed the activities of enzymes involved in fatty acid synthesis in the liver of OLETF rats. Moreover, dietary HPs lowered plasma MCP-1, fasting blood glucose, and HbA1c levels in these rats. Thus, dietary HPs may exert an ameliorative function on hepatic fatty acid metabolism, glucose metabolism, and inflammatory response accompanying the increase of the adipose tissue mass under obesity progression. In this study, the number of animals was low, and the level of dietary HPs was high; therefore, further experiments must be performed in a large number of animals or in condition of low level of dietary HPs to more precisely evaluate the functions of dietary HPs.

\section{References}

1) Li, Y.; Yatsuya, H.; Iso, H.; Tamakoshi, K.; Toyoshima, H. Incidence of metabolic syndrome according to combinations of lifestyle factors among middle-aged Japanese male workers. Prev. Med. 51, 118-122(2010).

2) Hill, J. O.; Wyatt, H. R.; Reed, G. W.; Peters, J. C. Obesity and the environment: where do we go from here? Science. 299, 853-855(2003).

3) Hu, F. B.; Manson, J. E.; Stampfer, M. J.; Colditz, G.; Liu, S.; Solomon, C. G.; Willett, W. C. Diet, Lifestyle, and the Risk of Type 2 Diabetes Mellitus in Women. $N$. Engl. J. Med. 345, 790-797(2001).

4) Maggio, C. A.; Pi-Sunyer, F. X. Obesity and type 2 diabetes. Endocrinology \& Metabolism Clinics of North America. 32, 805-822(2003).

5) Wilson, P. W.; D’ Agostino, R. B.; Sullivan, L.; Parise, H. \& Kannel, W. B. Overweight and obesity as determinants of cardiovascular risk. Arch. Intern. Med.162, 1867-1872(2002).

6) Wolk, A.; Gridley, G.; Svensson, M.; Nyrén, O.; McLaughlin, J. K.; Fraumeni, J. F.; Adam, H. O. A prospective study of obesity and cancer risk (Sweden). Cancer Causes and Control. 12, 13-21 (2001).

7) Ferquson, L. R. Role of plant polyphenols in genomic stability. Mutat. Res. 18, 89-111 (2001).

8) Rizvi, S. I.; Zaid, M. A.; Anis, R. \& Mishra, N. A Protective role of tea catechins against oxidation-induced damage of type 2 diabetic erythrocytes. Clin. Exp. Pharmacol. Physiol. 32, 70-75(2005).

9) Kobayashi, H.; Tanaka, Y.; Asagiri, K.; Asakawa, T.; Tanikawa, K.; Kage, M.; Yagi, M. The antioxidant effect of green tea catechin ameliorates experimental liver injury. Phytomedicine. 17, 197-202(2010).

10) Murase, T.; Nagasawa, A.; Suzuki, J.; Hase, T.; Tokimit- su, I. Beneficial effects of tea catechins on diet-induced obesity: stimulation of lipid catabolism in the liver. Int. J. Obes. Relat. Metab. Disord. 26, 14591464 (2002).

11) Furuyashiki, T.; Nagayasu, H.; Aoki, Y.; Bessho, H.; Hashimoto, T.; Kanazawa, K.; Ashida, H. Tea catechin suppresses adipocyte differentiation accompanied by down-regulation of $\mathrm{PPAR} \gamma_{2}$ and $\mathrm{C} / \mathrm{EBP} \alpha$ in 3T3-L1 cells. Biosci. Biotechnol. Biochem. 68, 2353-2359 (2004).

12) Azuma, K.; Ippoushi, K.; Terao, J. Evaluation of tolerable levels of dietary quercetin for exerting its antioxidative effect in high cholesterol-fed rats. Food Chem. Toxicol. 48, 1117-1122(2010).

13) Nizamutdinova, I. T.; Jin, Y. C.; Chung, J. I.; Shin, S. C.; Lee, S. J.; Seo, H. G.; Lee, J. H.; Chang, K. C.; Kim, H. J. The anti-diabetic effect of anthocyanins in streptozotocin-induced diabetic rats through glucose transporter 4 regulation and prevention of insulin resistance and pancreatic apoptosis; Mol. Nutr. Food. Res. 53, 1419-1429 (2009).

14) Jing, H.; Deinzer, M. L. Proanthocyanidins in Hops. Beer in health and disease prevention. 32, 333-348 (2009).

15) Osada, K. Funayama M. Fuchi S. Sami M. Ohta T. Kanada T.; Ikeda M. Effects of dietary procyanidins and tea polyphenols on adipose tissue mass and fatty acid metabolism in rats on a high fat diet. J. Oleo Sci. 55, 79-89 (2006).

16) Montagut, G.; Onnockx, S.; Vaqué, M.; Bladé, C.; Blay, M.; Fernández-Larrea, J.; Pujadas, G.; Salvadó, M. J.; Arola, L.; Pirson, I.; Ardévol, A.; Pinent, M. Oligomers of grape-seed procyanidin extract activate the insulin receptor and key targets of the insulin signaling pathway differently from insulin. J. Nutr. Biochem. 21, 476-81 (2010).

17) Hai, C. Z,; Yi, M. L.; Yuan, Y. L.; Min, L.; Shu, D. W.; Wei, M. C.; Nora, F. T. Antioxidant properties of polymeric proanthocyanidins from fruit stones and pericarps of Litchi chinensis Sonn. Food Res. Int. 44, 613620 (2011).

18) Yahiro, K.; Shirasaka, D.; Tagashira, M.; Wada, A.; Morinaga, N.; Kuroda, F.; Choi, O.; Inoue, M.; Aoyama, N.; Ikeda, M.; Hirayama, T.; Moss, J.; Noda, M. Inhibitory effects of polyphenols on gastric injury by Helicobacter pylori VacA toxin. Helicobacter. 10, 231-239 (2005).

19) Yaegaki, K.; Tanaka, T.; Sato, T.; Murata, T.; Imai, T.; Tagashira, M.; Akazome, Y.; Hirai, N.; Ohtake, Y. Hop polyphenols suppress production of water-insoluble glucan by Streptococcus mutans and dental plaque growth in vivo. J. Clin. Dent. 19, 74-78(2008).

20) Stevens, J. F.; Miranda, C. L.; Wolthers, K. R.; Schimerlik, M.; Deinzer, M. L.; Buhler, D. R. Identification and 


\section{K. Yui, H. Uematsu, K. Muroi et al.}

in vitro biological activities of hop proanthocyanidins: inhibition of nNOS activity and scavenging of reactive nitrogen species. J. Agri.c Food Chem. 50, 3435-3443 (2002).

21) Reeves, P. G.; Nielsen, F. H.; Fahey.; G. C. Jr. AIN-93 purified diets for laboratory rodents: final report of the American Institute of Nutrition ad hoc writing committee on the reformulation of the AIN-76A rodent diet. J Nutr. 12, 1939-1951 (1993).

22) Folch, J.; Lees, M.; Sloane, S. G. H. A simple Method for the Isolation and Purification of Total Lipid from animal Tissues. J. Biol. Chem. 226, 497-506 (1957).

23) Ide, T.; Okamatu, H.; Sugano, M. Regulation by dietary fats of 3-hydroxy-3-metyhlglutaryl coenzyme a reductase in rat livers. J. Nutr. 108, 601-602(1978).

24) Burchard, H. Beitrage zue Kenntnins des Cholesterins. Chem. Zentralbl. 61, 25-27(1890).

25) Rouserand, G.; Siakotos, A. N.; Fleiscer, S. Quantitatibe analysis of phospholipids by thin-layer chromatography and phosphorus analysis of spot. Lipid. 1, 85-86 (1966).

26) Nepokroeff, C. M.; Lakshmanan, M. R.; Porter, J. W. Fatty acid synthase from rat liver. Methods in Enzymology. 35, 37-44 (1975).

27) Dror, Y.; Sassoon, H. F.; Watson, J. J.; Johnson, B. C. Glucose 6-phosphate dehydrogenase assay in liver and blood. Clin. Chim. Acta. 28, 291-298(1970).

28) Pongratz, R. L.; Kibbey, R. G.; Cline, G. W. Investigating the roles of mitochondrial and cytosolic malic enzyme in insulin secretion. Methods Enzymol. 457, 425-50 (2009).

29) Osumi, T.; Hashimoto, T. Acyl-CoA oxidase of rat liver: A new enzyme for fatty acid oxidation. Biochem. Biophys. Res. Commun. 83, 479-485(1978).

30) Markwell, M. A.; McGroarty, E. J.; Biber, L. L.; Tolbert, N. E. The subcellular distribution of carnitine acyltransferases in mammalian liver and kindney. A new peroxisomal enzyme. J. Biol. Chem. 25, 3426-3432 (1973).

31) Jung, U. J.; Lee, M. K.; Park, Y. B.; Kang, M. A.; Choi, M. S. Effect of citrus flavonoids on lipid metabolism and glucose-regulating enzyme mRNA levels in type-2 diabetic mice. Int. J. Biochem. Cell. Biol. 38, 1134-1145 (2006).

32) Uchiyama, S.; Taniguchi, Y.; Saka, A; Yoshida, A.; Yajima, H. Prevention of diet-induced obesity by dietary black tea polyphenols extract in vitro and in vivo. $\mathrm{Nu}$ trition. 27, 287-292(2011).

33) Kolehmainen, M.; Vidal, H.; Alhava, E.; Uusitupa, M. I. J. Sterol regulatory element binding protein 1c (SREBP-1c) expression in human obesity. Obes. Res. 9, 706-712(2001).

34) Kin J. B.; Spigelman B. M. ADD1/SREBP1 promotes adipocyte differentiation and gene expression linked to fatty acid metabolism. Genes Dev. 10, 1096-1107 (1996).

35) Yokoyama, C.; Wang, X.; Briggs, MR.; Admon, A.; Wu, J.; Hua, X.; Goldstein, J. L.; Brown, M. S. SREBP-1 a basic-helix loop-helix-leucine zipper protein that controls transcription of the low density lipoprotein receptor gene. Cell, 75, 187-197(1993).

36) Shoji, T.; Masumoto, S.; Moriichi, N.; Akiyama, H.; Kanda, T.; Ohtake, Y.; Goda, Y. Apple procyanidin oligomers absorption in rats after oral administration: Analysis of procyanidins in plasma using the porter method and high-performance liquid chromatography/ tandem mass spectrometry. J. Agric. Food Chem. 54, 884-892 (2006).

37) Qiang, H.; Yuanping, L.; Kai, Y. Effects of tea polyphenol on the activities of $\alpha$-amylase,pepsin,trypsin and lipase. Food Chem. 101, 1178-1182(2006).

38) Ogino, Y.; Osada, K.; Nakamura, S.; Ohta, Y.; Kanda, T.; Sugano, M. Absorption of dietary cholesterol oxidation products and their downstream metabolic effects are reduced by dietary apple polyphenols. Lipids. 42, 151-161 (2007).

39) Qin, B.; Polansky, M. M.; Harry, D.; Anderson, R. A. Green tea polyphenols improve cardiac muscle mRNA and protein levels of signal pathways related to insulin and lipid metabolism and inflammation in insulinresistant rats. Mol. Nutr. Food Res. 54, 14-23. (2010)

40) Anderson, R. A.; Polansky, M. M. Tea enhances insulin activity. J. Agric. Food Chem. 50, 7182-7186(2002).

41) Matsui, T.; Tanaka, T.; Tamura, S.; Toshima, A.; Tamaya, K.; Miyata, Y.; Tanaka, K.; Matsumoto, K. alphaGlucosidase inhibitory profile of catechins and theaflavins. J. Agric. Food. Chem. 55, 99-105(2007).

42) Kamiyama, O.; Sanae, F.; Ikeda, K.; Higashi, Y.; Minami, Y.; Asao, N.; Adachi, I.; Kato, A. In vitro inhibition of $\alpha$-glucosidases and glycogen phosphorylase by catechin gallates in green tea. Food Chem. 122, 10611066 (2010).

43) Schafer, A.; Hogger, P. Oligomeric procyanidins of French maritime pine bark extract (Pycnogenol)effectively inhibit $\alpha$-glucosidase. Diabetes Rese. Clin. Pract. 77, 41-46(2007).

44) Gu, L.; Okada, Y.; Clinton, S. K.; Gerard, C.; Sukhova, G. K.; Libby, P.; Rollins, B. J. Absence of monocyte chemoattractant protein-1 reduces atherosclerosis in low density lipoprotein receptor-deficient mice. Mol. Cell. 2, 275-281 (1998).

45) Kanda, H.; Tateya, S.; Tamori, Y.; Kotani, K.; Hiasa, K.; Kitazawa, R.; Kitazawa, S.; Miyachi, H.; Maeda, S.; Egashira, K.; Kasuga, M. MCP-1 contributes to macrophage infiltration into adipose tissue, insulin resistance, and hepatic steatosis in obesity. J. Clin. Invest. 116, 1494-1505 (2006). 